Clinical Medicine

Poster

Abstract ID: 143

\title{
Quantification of pterygium fibroconnective components utilizing freeze-dried method
}

\author{
Mohd Radzi Hilmi ${ }^{\mathrm{a}}$ | Khairidzan Mohd Kamal ${ }^{\mathrm{b}}$ | Mohd Zulfaezal Che Azemin ${ }^{\mathrm{a}}$ | Azrin Esmady Ariffin ${ }^{\mathrm{c}}$ \\ ${ }^{a}$ Department of Optometry and Vision Sciences, Kulliyyah of Allied Health Sciences, International \\ Islamic University Malaysia \\ ${ }^{b}$ Department of Ophthalmology, Kulliyyah of Medicine, International Islamic University Malaysia \\ ${ }^{c}$ Faculty of Optometry and Vision Science, SEGi University, Malaysia
}

Introduction: To propose an objective method of quantifying pterygium fibroconnective components utilizing freeze-dried method. Methods: 60 primary pterygium were excised using controlled partial avulsion technique performed by a single surgeon (KMK), and divided into two groups: formalin-fixed $(n=30)$ and fresh $(n=30)$. Initially, each sterile container weight was measured and $5 \mathrm{ml}$ of $5 \%$ buffered formaldehyde were filled and stored for 1 week for formalin-fixed group while, $5 \mathrm{ml}$ distilled water were filled for fresh pterygium group. Each container was pre-frozen for 12 hours prior to freeze-dried $\left(-80^{\circ} \mathrm{C}\right.$ for 24 hours). The final product known as fibroconnective tissue, then weighted as dry weight. Comparative analysis of wet and dry weight, and percentage of fibroconnective components between groups were performed via an independent t-test. Results: The overall mean and SD for formalin-fixed and fresh pterygium wet weight were $253.33 \pm$ $82.17 \mu \mathrm{g}$ and $255.17 \pm 63.52 \mu \mathrm{g}$, and dry weight were $184.92 \pm 84.31 \mu \mathrm{g}$ and $179.54 \pm 72.85$ $\mu \mathrm{g}$ respectively. In terms of percentage of fibroconnective components, formalin-fixed group revealed slightly higher percentage compared to fresh pterygium tissue with $69.39 \pm$ $13.29 \%$ and $67.75 \pm 13.27 \%$ respectively. The difference in pterygium dry weight, between formalin-fixed and fresh pterygium tissue was statistically insignificant $(p=0.792)$. Conclusions: The freeze-dried method can be used to quantify the fibroconnective component (dry weight) of pterygium fibro vascular tissue. Both methods (formalin-fixed and freeze-dried) are reliable in producing results. This is proven as there is no statistical significance between the two methods.

KEYWORDS: Pterygium, fibroconnective, freeze-dried, dry weight 